\title{
Mycobacterium avium infection of gut mucosa in mice associated with late inflammatory response and intestinal cell necrosis
}

\author{
S. Y. KIM, J. R. GOODMAN*, MARY PETROFSKY and L. E. BERMUDEZ \\ Kuzell Institute for Arthritis and Infectious Diseases, California Pacific Medical Center Research Institute, \\ San Francisco, CA 94115 and *Department of Pediatric Electron Microscopy, University of California \\ San Francisco, San Francisco, CA 94143, USA
}

\begin{abstract}
Mycobacterium avium is an intracellular pathogen that is associated with disseminated infection in acquired immunodeficiency syndrome (AIDS). Patients with AIDS appear to acquire $M$. avium mainly through the gastrointestinal tract. Previous studies have shown that healthy mice given $M$. avium orally develop disseminated infection after $2-4$ weeks. The chief site of $M$. avium invasion of the intestinal mucosa is the terminal ileum. To learn more about the pathophysiology of $M$. avium infection of the intestinal mucosa, C57BL $/ 6 \mathrm{bg}+\mathrm{bg}+$ mice were infected orally with $M$. avium strain 101 and groups of six mice were killed each week for 8 weeks. The terminal ileum was then prepared for histopathological studies and electron microscopy. A delayed inflammatory response was observed and influx of neutrophils in the Peyer's patches was the only abnormality seen at 1 week. A severe inflammatory response was seen from week 2 to week 5 and necrosis of intestinal villi was observed 6 weeks after infection. These results indicate that invasion and infection of the normal intestine by $M$. avium results in a severe inflammatory response with segmental necrosis of the intestinal mucosa.
\end{abstract}

\section{Introduction}

Mycobacterium avium is an intracellular pathogen that can cause disseminated infection in patients with acquired immunodeficiency syndrome (AIDS), as well as in patients with other long-term immunosuppressive diseases [1-3]. In AIDS patients, $M$. avium infection is mainly acquired through the gastrointestinal tract [4] although the respiratory tract has been described as the route of infection in a small percentage of patients [5]. Some studies have shown that colonisation of the gastrointestinal tract precedes the isolation of $M$. avium in blood and tissues by weeks to months [6].

Recent studies have demonstrated that $M$. avium is capable of invading intestinal mucosal cells in vitro $[7,8]$ and the intestinal mucosa of healthy mice in vivo [9]. The ability to enter the intestinal mucosa in vivo was strain-dependent. It was observed that the preferential sites of $M$. avium entry were the terminal ileum and the ascending colon [9] suggesting that the

Received 22 July 1997; accepted 17 Dec. 1997.

Corresponding author: Dr L. E. Bermudez.
Peyer's patches are involved in the process of $M$. avium uptake. Histopathological studies of intestines of AIDS patients with disseminated $M$. avium infection have shown a large number of organisms in the mucosal epithelial cells and in the lamina propria of the intestines, usually within macrophages [10]. $M$. avium within regional lymph nodes is commonly observed in autopsy studies $[10,11]$.

Despite these recent findings, little is known about the pathogenesis of $M$. avium infection of the intestinal tract in AIDS. Therefore, to better understand the

Table 1. Number of $M$. avium in the terminal ileum of beige mice at several weeks after oral infection

\begin{tabular}{lc}
\hline Weeks* & $\begin{array}{c}\text { Mean (SEM) number of } \\
\text { bacteria/g of tissue }\end{array}$ \\
\hline 1 & $2.4(0.5) \times 10^{3}$ \\
2 & $4.7(0.4) \times 10^{4}$ \\
4 & $6.1(0.6) \times 10^{5}$ \\
6 & $1.1(0.4) \times 10^{6}$ \\
8 & $3.5(0.7) \times 10^{7}$ \\
\hline
\end{tabular}

${ }^{*}$ Mice were infected orally with $5 \times 10^{8}$ bacteria. Control mice (given buffer instead) showed no evidence of $M$. avium infection. 
a

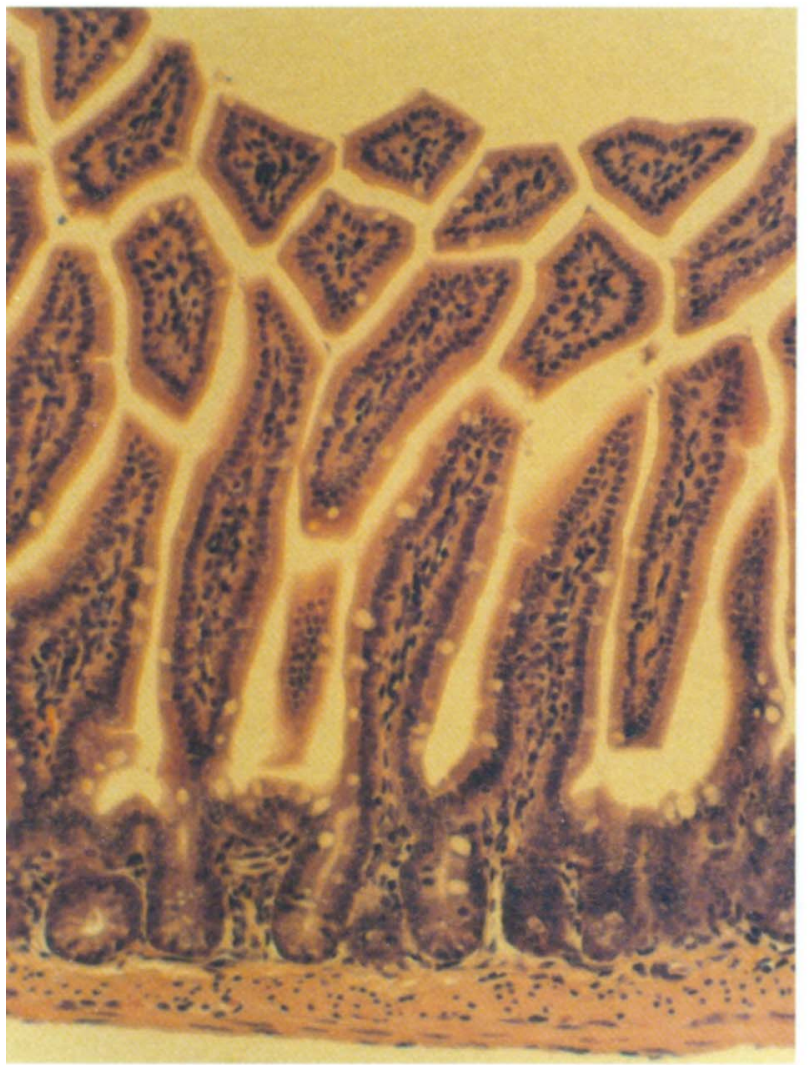

\section{b}

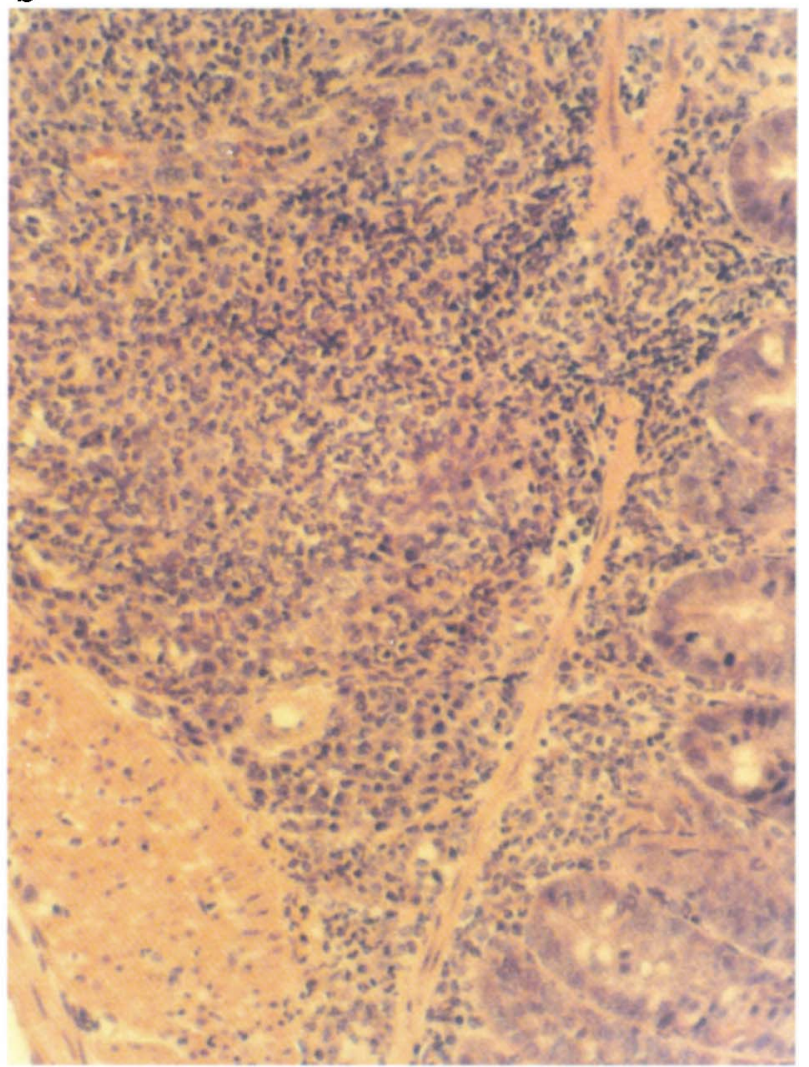

C

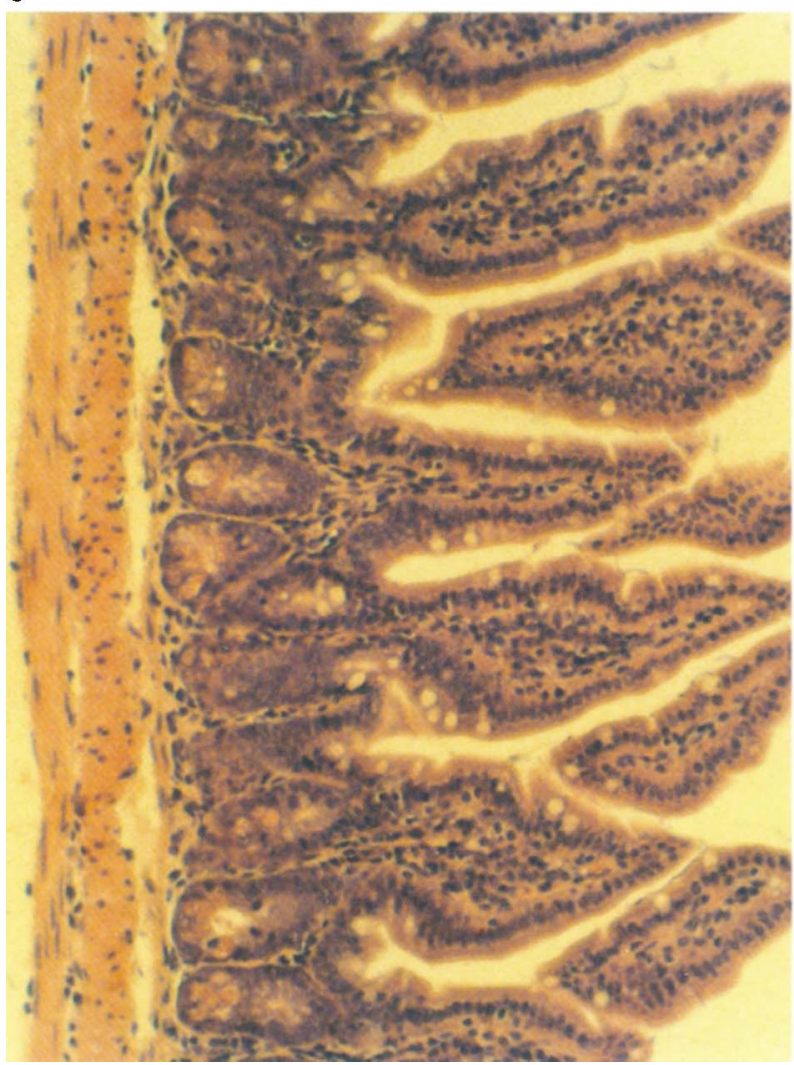

d

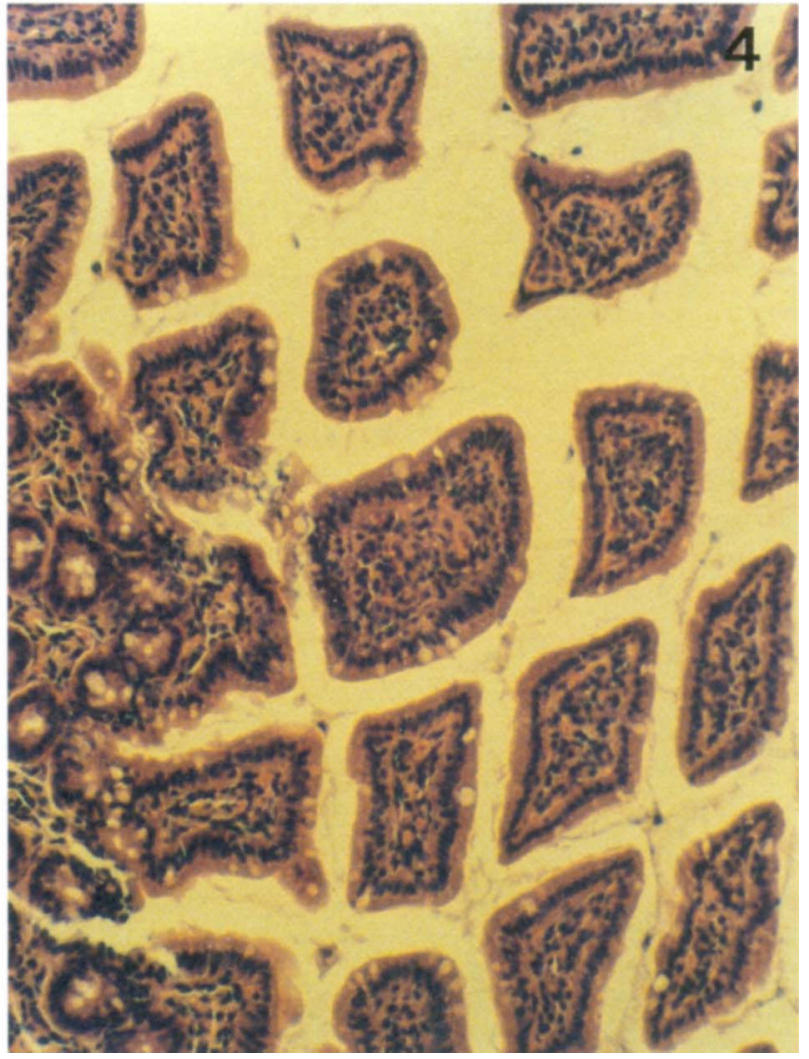

Fig. 1. (a) Intestinal mucosa of control mice. (b) Peyer's patches from mice infected for 1 week, showing infiltrate of polymorphonuclear leucocytes. (c) Congestion and oedema of the mucosal villi can be observed 2 and 3 weeks after infection. The inflammatory cells are mainly lymphocytes. (d) At weeks 4 and 5, oedema and lymphocyte infiltration were found more extensively. Focal drop-out of mucosal epithelial cells is also seen. 


\section{e}

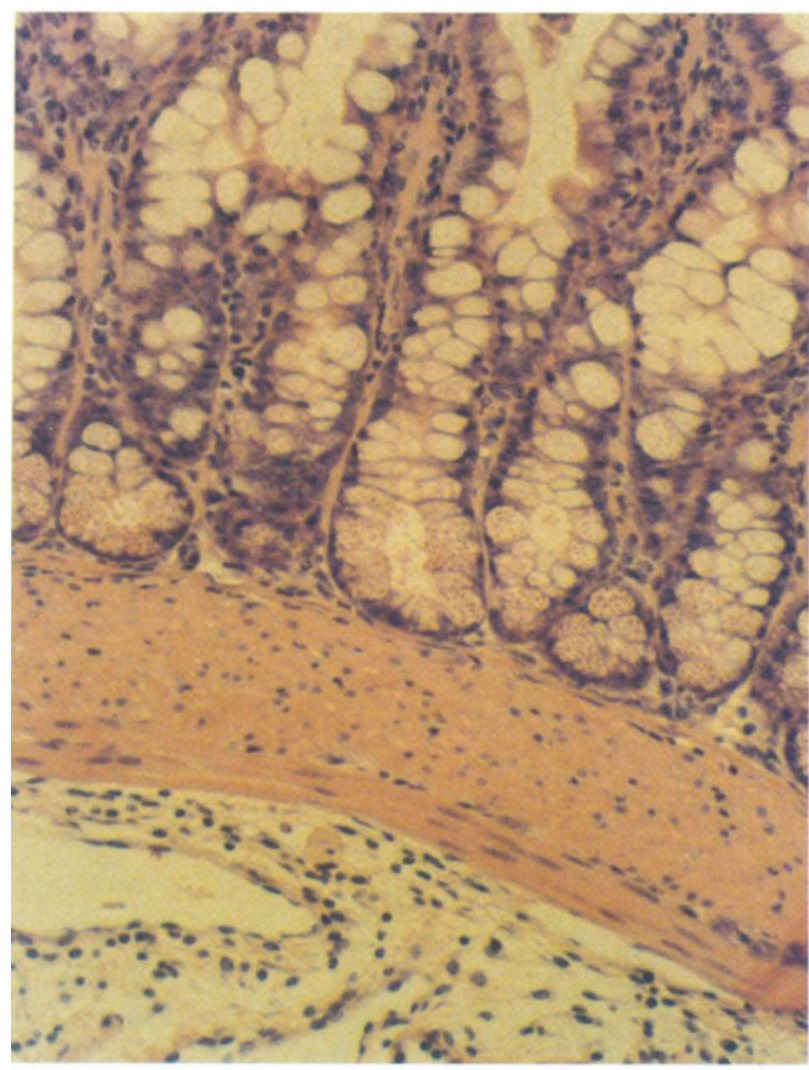

f

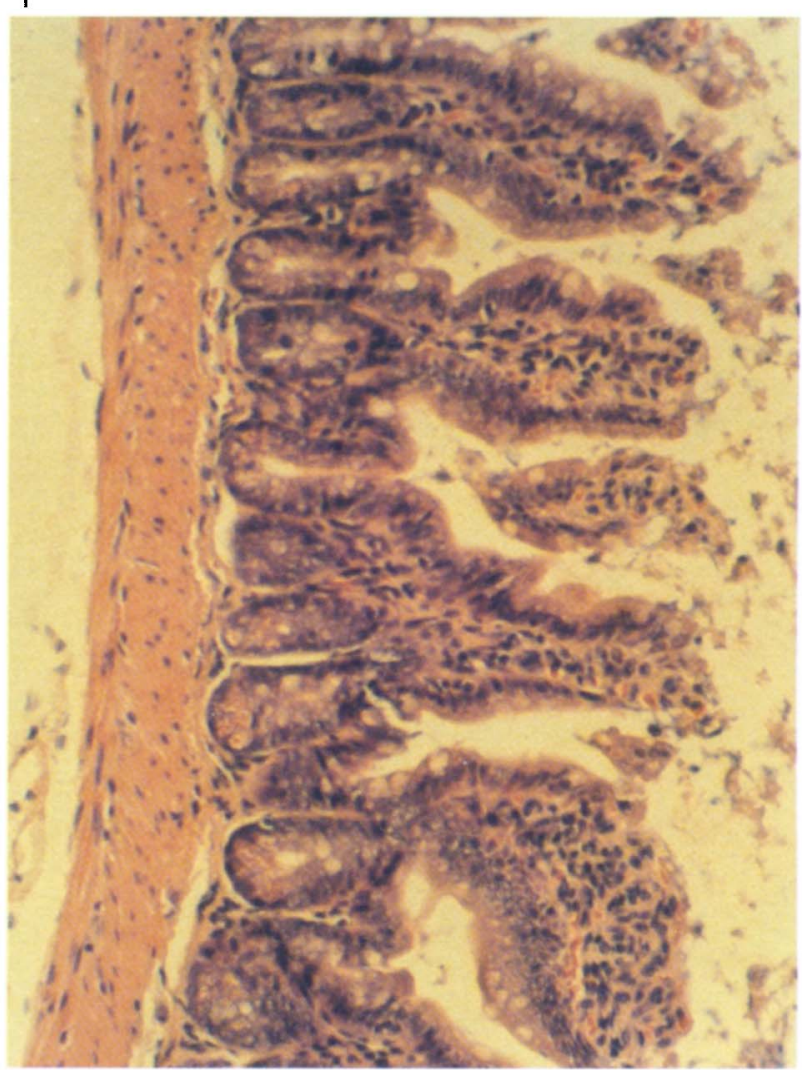

g

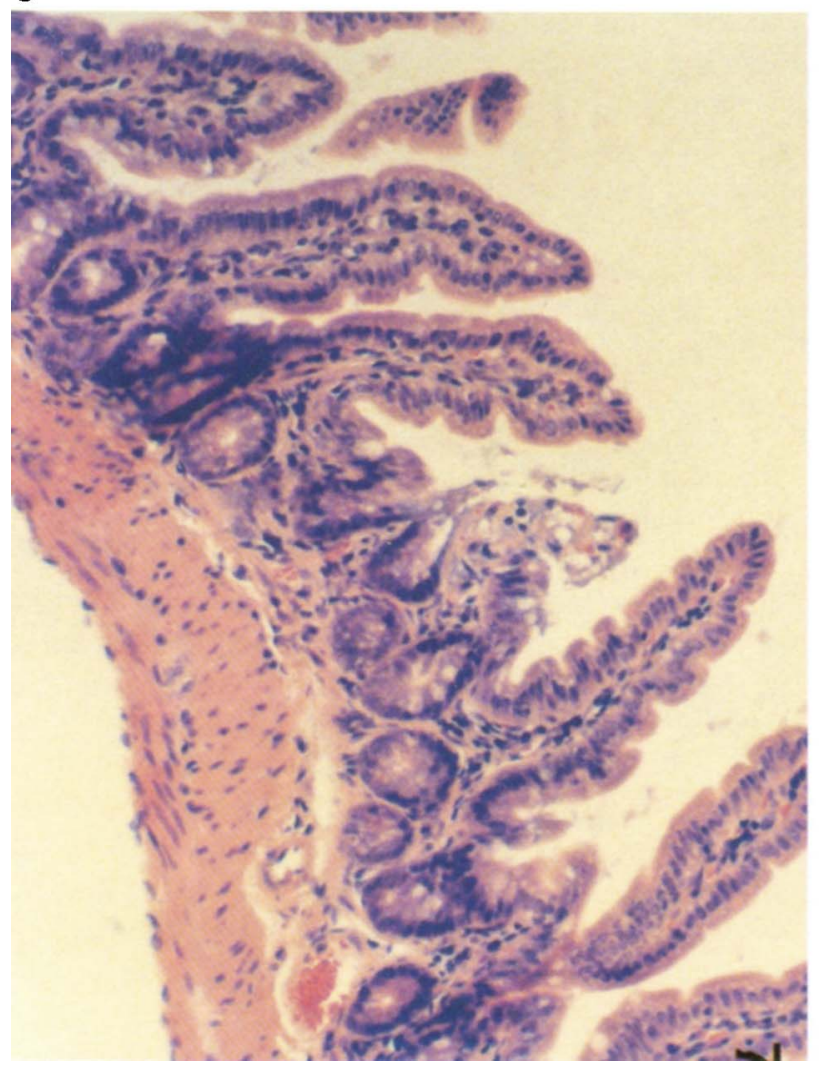

h

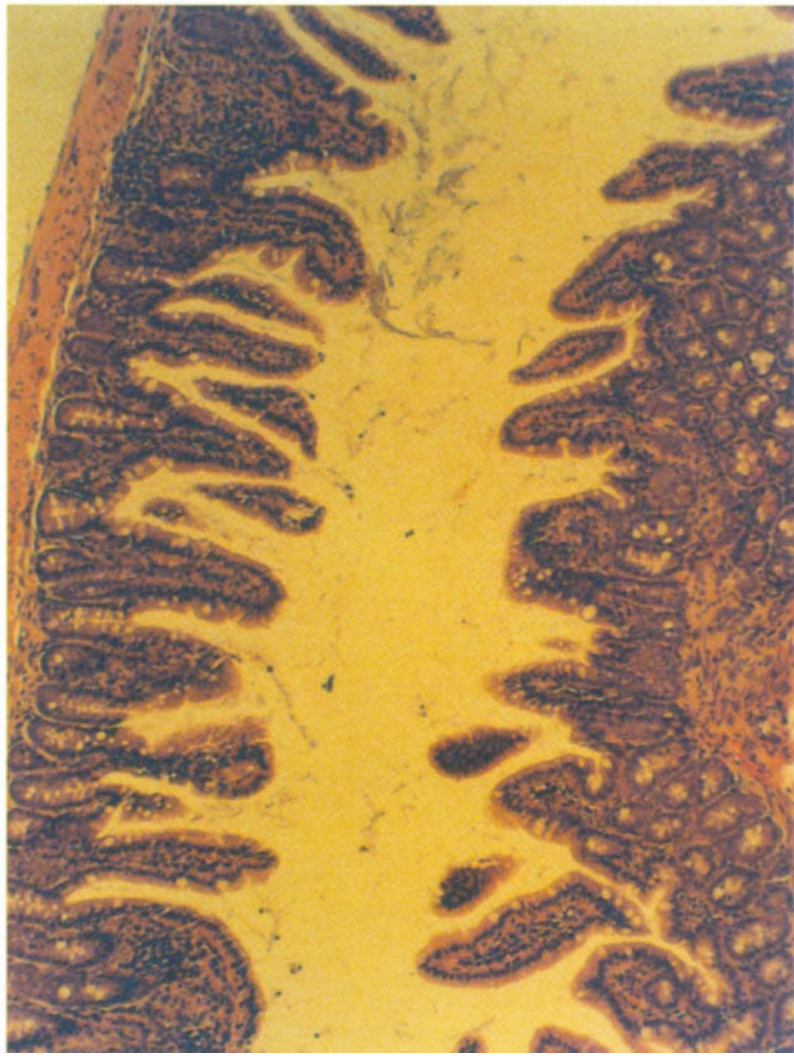

Fig. 1. (e) At weeks 4 and 5, increase in the number of goblet cells and Paneth's cells and infiltration of inflammatory cells in the serosa can be observed. (f) Degenerating apical portions of intestinal villi were observed 6-8 weeks after oral challenge. (g) Total necrosis of a villus and mucosal regeneration (scalloping of epithelial surface) in neighbouring villi were also observed 6-8 weeks after oral challenge. (h) Focal areas of mucosal fibrosis and fusion of the villi were seen 8 weeks after oral challenge. 
evolution of gastrointestinal infection in AIDS patients, systematic studies were carried out with beige mice infected orally with $M$. avium and the intestinal infection was followed for 8 weeks.

\section{Materials and methods}

Mice

C57BL/6 female beige mice were obtained from Jackson Laboratory (Bar Harbor, ME, USA). Mice were $8-10$ weeks old at the time of infection.

\section{Bacteria}

$M$. avium strain 101 was obtained from the blood of an AIDS patient. $M$. avium 101 is a virulent strain that produces a predictable degree of infection in C57BL/ 6 beige mice [12]. M. avium 101 (serovar 1) was grown in Middlebrook 7H11 agar (Difco Laboratories, Detroit, MI, USA) with oleic acid, albumin, dextrose and catalase for 10 days at $37^{\circ} \mathrm{C}$. For the experiments, sufficient bacteria were harvested, washed in Hanks's Balanced Salts Solution (HBSS) and adjusted to a concentration of $5 \times 10^{9}$ bacteria $/ \mathrm{ml}$.

\section{Infection}

Mice were infected orally, by lavage, with $0.2 \mathrm{ml}$ of a suspension containing $5 \times 10^{8}$ bacteria (six mice were infected per timepoint). Three uninfected control mice that received only buffer orally were used in the assay. At weeks $0,1,2,3,4,5,6,7$ and 8, mice were killed (control and infected) and the terminal ileum was removed for histology and electron microscopy. At weeks 1, 2, 4, 6 and 8 , intestine was also obtained from six mice/timepoint for quantification of viable mycobacteria [9].

\section{Histology}

Terminal ileum was removed from six mice/timepoint, fixed in buffered formalin ( $\mathrm{pH}$ 6.9), and processed and stained with haematoxylin and eosin (H \& E).

\section{Electron microscopy}

Intestinal segments were cut longitudinally and extensively washed with HBSS. The segments were then fixed in ice-cold glutaraldehyde $1 \%$ in phosphate buffer overnight, and post-fixed with $\mathrm{OsO}_{4} \quad 1 \%$ at room temperature for $1 \mathrm{~h}$. The intestinal segments were then dehydrated through $50 \%$ and $80 \%$ ethyl ethanol at room temperature, embedded in LR white resin and polymerised at $52^{\circ} \mathrm{C}$. Thin sections were cut and stained with uranyl acetate and lead citrate. Electron micrographs were obtained with a transmission electron microscope.

\section{Quantification of $M$. avium}

Quantification of $M$. avium in the terminal ileum was carried out as described previously [9]. Briefly, a $5-\mathrm{cm}$ segment of the terminal ileum was removed aseptically, cut longitudinally and extensively washed in PBS ( $\mathrm{pH}$ 7.2). The segment was then weighed, suspended and homogenised in Middlebrook 7H9 broth (Difco) and serially diluted in $7 \mathrm{H} 9$ broth. Samples of the suspension were plated on to $7 \mathrm{H} 11$ agar supplemented with oleic acid, albumin, dextrose and catalase. The plates were incubated for $8-10$ days at $37^{\circ} \mathrm{C}$ and after counting the number of bacteria was expressed as mean (SEM) $\mathrm{cfu} / \mathrm{g}$ of tissue.

\section{Results}

\section{M. avium load in the terminal ileum}

To verify whether $M$. avium given orally either attached to or entered the intestinal mucosa, groups of mice given $5 \times 10^{8}$ bacteria and control mice were killed after 1 week and then bi-weekly for 8 weeks and the number of bacteria in the terminal ileum quantified. As shown in Table 1, the bacterial load associated with the gut mucosa increased progressively from week 1 until week 8 (this method does not allow differentiation between binding and entry). No $M$. avium was isolated from the terminal ileum mucosa of uninfected control mice.

\section{Histopathological observations}

The intestines of the control mice had normal intestinal villi showing a well-preserved epithelial lining with an even brush border and narrow core with a few mononuclear inflammatory cells. The muscle coats had even thickness and the serosa showed no inflammatory cells (Fig. 1a).

Toward the end of first week after $M$. avium ingestion, the intestines showed the same histological findings as the control except for focal severe inflammation around the Peyer's patches. The lymphoid tissue and the mucosa overlying the patches were heavily infiltrated with polymorphonuclear leucocytes (PMNLs) and mononuclear cells (Fig. 1b).

Two or 3 weeks after infection, swelling of the mucosal villi was noted with congestion and oedema. The inflammatory cells, exclusively lymphocytes, had infiltrated the swollen lamina propria (Fig. 1c).

After 4-5 weeks, swelling and lymphocytic infiltration in the mucosa were found more extensively. Some tip portions of the villi showed irregular brush borders and degeneration of epithelial cells. Focal drop-out of epithelial cells was also noted at this stage (Fig. 1d). Some segments showed prominent increase of goblet cells and Paneth's granular cells, and showed serosal oedema with inflammatory cell infiltration (Fig. 1e).

Between 6 and 8 weeks after infection, the tip portions of the villi showed abrupt exposure of degenerating subepithelial connective tissue resulting 
from necrosis of the tip portion. The lumen contained necrotic debris (Fig. 1f). Most of the sloughed lesions were limited to the tips of the villi. However, there were some foci of complete villus loss resulting in pin-point ulceration. The necrotic lesions were seen focally or segmentally with intervening areas of mild or minimal inflammation. The intervening areas showed signs of healing such as scalloping of wellpreserved brush border and frequent hyperchromatic nuclei in the epithelium (Fig. 1g). Also seen were a few healed foci leaving sequelae such as fusion of the villi, focal fibrosis of the mucosa and irregular thickening of muscle coats (Fig. 1h).

\section{Electron microscopy}

Because of the histopathological findings described above, suggesting necrosis of villi as a mechanism

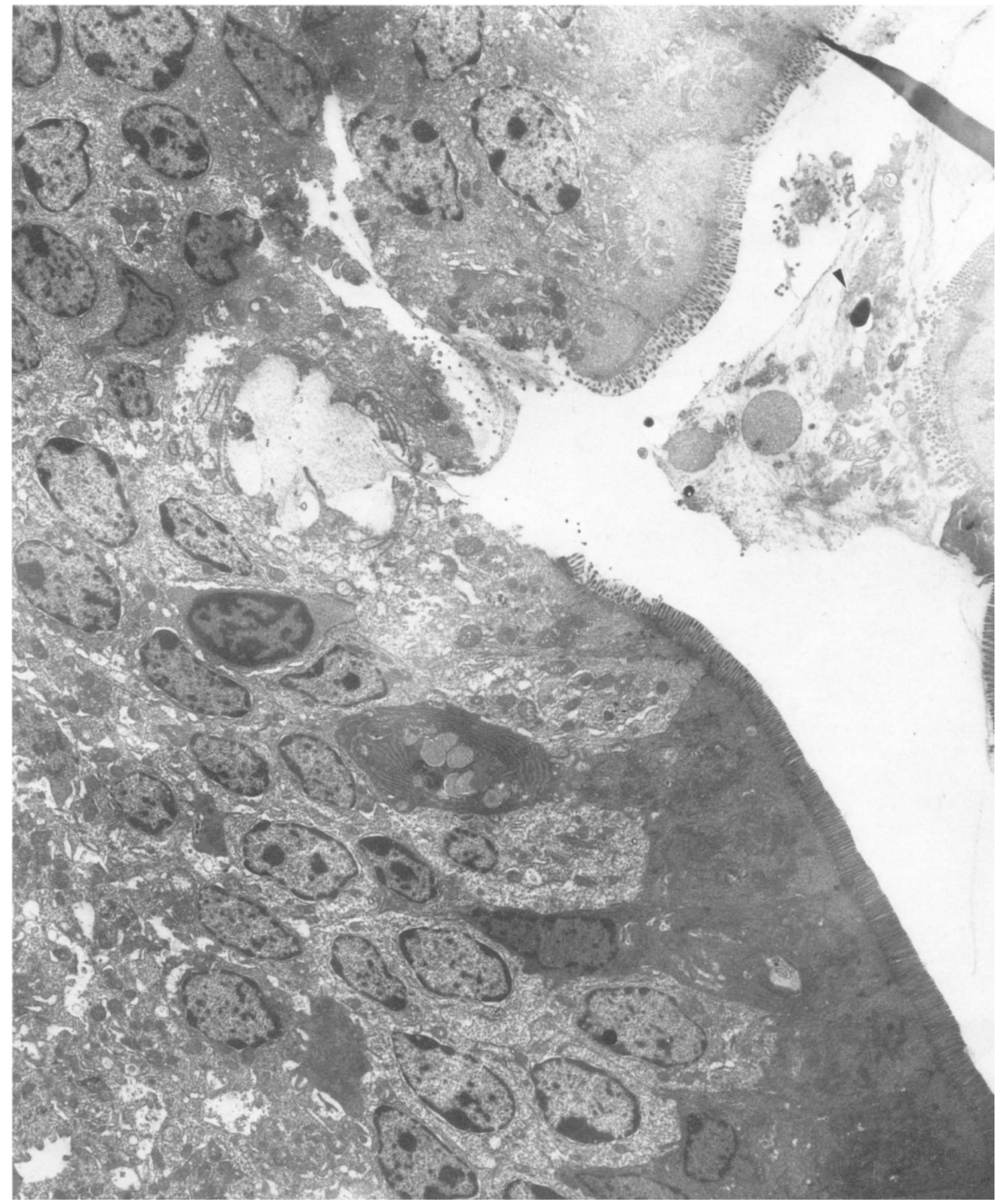

Fig. 2. Electron micrograph showing a segment of Peyer's patches 2 weeks after oral challenge. Necrosis of an enterocyte is shown with the release of an intracellular bacterium (arrowhead). 
7. Bermudez LE, Young LS. Factors affecting invasion of HT-29 and HEp-2 epithelial cells by organisms of the Mycobacterium avium complex. Infect Immun 1994; 62: 2021-2026

8. Bermudez LE, Shelton K, Young LS. Comparison of the ability of Mycobacterium avium, $M$. smegmatis, and $M$. tuberculosis to invade and replicate within HEp-2 epithelial cells. Tubercle Lung Dis 1995; 76: 240-247.

9. Bermudez LE, Petrofsky M, Kolonoski P, Young LS. An anima model of Mycobacterium avium complex disseminated infection after colonization of the intestinal tract. $J$ Infect Dis 1992; 165: $75-79$.

10. Roth RI, Owen RL, Keren DF, Volberding PA. Intestinal infection with Mycobacterium avium in acquired immune deficiency syndrome (AIDS). Histological and clinical comparison with Whipple's disease. Dig Dis Sci 1985; 30: 497-504.

11. Steffen EK, Berg RD, Dietch EA. Comparison of translocation rates of various indigenous bacteria from the gastrointestinal tract to the mesenteric lymph node. J Infect Dis 1988; 157: 1032-1038.

12. Inderlied $\mathrm{CB}$, Kolonoski $\mathrm{PT}, \mathrm{Wu} \mathrm{M}$, Young $\mathrm{LS}$. In vitro and in vivo activity of azithromycin (CP 62, 993) against the Mycobacterium avium complex. I Infect Dis 1989; 159: 994-997.

13. Horsburgh CR. Advances in the prevention and treatment of Mycobacterium avium disease. $N$ Engl J Med 1996; 335 428-430.

14. Jung HC, Eckmann L, Yang S-K et al. A distinct array of proinflammatory cytokines is expressed in human colon epithelial cells in response to bacterial invasion. $J$ Clin Invest 1995; 95: 55-65.

15. Eckmann L, Kagnoff MF, Fierer J. Intestinal epithelial cells as watchdogs for the natural immune system. Trends Microbiol 1995; 3: 118-120.

16. Weinstein DL, O'Neill BL, Metcalf ES. Salmonella typhi stimulation of human intestinal epithelial cells induces secretion of epithelial cell-derived interleukin-6. Infect Immun 1997; 65: $395-404$.

17. Clark MA, Jepson MA, Simmons NL, Hirst BH. Preferential interaction of Salmonella typhimurium with mouse Peyer's patch M cells. Res Microbiol 1994; 145: 543-552.

18. Sansonetti PJ. Molecular and cellular biology of Shigella flexneri invasiveness: from cell assay systems to shigellosis. In: Sansonetti PJ (ed) Pathogenesis of shigellosis. Curr Top Microbiol Immunol 1992; 180: 1-19.

19. Sangari F, Petrofsky M, Bermudez LE. Mycobacterium avium inhibits early release of chemokines upon invasion of intestinal epithelial cells. Abstract, Keystone Symposium, Mucosal Immunity: Cellular and Molecular Cross-Talk at Mucosal Surfaces, 1997.

20. Giannasca KT, Giannasca PJ, Neutra MR. Adherence of Salmonella typhimurium to $\mathrm{CaCO}_{2}$ cells: identification of a glycoconjugate receptor. Infect Immun 1996; 64: 135-145.

21. Hultgren SJ, Abraham S, Caparon M, Falk P, Geme JWS Normark S. Pilus and nonpilus adhesions: assembly and function in cell recognition. Cell 1993; 73: 887-901. 
